\title{
All-Trans Retinoic Acid-Induced Pseudotumor Cerebri during Induction Therapy for Acute Promyelocytic Leukemia: A Case Report and Literature Review
}

\author{
Dylan Holmes, ${ }^{1}$ Prakash Vishnu, ${ }^{1}$ Russell K. Dorer, ${ }^{2}$ and David M. Aboulafia ${ }^{1,3}$ \\ ${ }^{1}$ Floyd \& Delores Jones Cancer Institute, Virginia Mason Medical Center, Seattle, WA 98101, USA \\ ${ }^{2}$ Department of Pathology, Virginia Mason Medical Center, 1100 Seattle, WA 98101, USA \\ ${ }^{3}$ Division of Hematology, University of Washington, Seattle, WA 98195, USA
}

Correspondence should be addressed to Prakash Vishnu, prakash.vishnu@vmmc.org

Received 5 February 2012; Accepted 1 April 2012

Academic Editors: S. Aksoy, M. W. Bekkenk, A. Goodman, and O. Ozyilkan

Copyright ( $\odot 2012$ Dylan Holmes et al. This is an open access article distributed under the Creative Commons Attribution License, which permits unrestricted use, distribution, and reproduction in any medium, provided the original work is properly cited.

\begin{abstract}
All-trans retinoic acid (ATRA), a derivative of vitamin A, is an essential component in the treatment of acute promyelocytic leukemia (APL). Though considered to be a relatively safe drug, use of ATRA can lead to several side effects such as retinoic acid syndrome and pseudotumor cerebri (PC). PC is a rare disorder characterized by neurologic and ocular signs and symptoms of increased intracranial pressure, but with normal cerebrospinal fluid composition and normal brain imaging. Most of the previous studies suggest that PC, as a complication of ATRA therapy, occurs predominantly in the pediatric age group. Herein, we report a rare case of ATRA-induced PC in a 38-year-old woman undergoing induction treatment for APL. Symptoms improved with discontinuation of ATRA and treatment with acetazolamide. Concomitant administration of medications such as triazole antifungals which influence the cytochrome P-450 system can exacerbate this potential complication of ATRA. In this paper, we also review the current literature, provide a descriptive analysis of clinical features, and discuss the principles of management of ATRA-induced PC.
\end{abstract}

\section{Introduction}

Acute promyelocytic leukemia (APL) is a distinct clinicopathologic disorder that accounts for $10 \%$ to $15 \%$ of cases of acute myeloid leukemia (AML). The unique features of APL have been well chronicled $[1,2]$ and include a characteristic morphologic appearance [3]; a reciprocal translocation between the long arm of chromosomes 15 and 17, leading to fusion of promyelocytic leukemia (PML)-promoter gene to the retinoic acid receptor (RAR)- $\alpha$ gene, which results in the formation of $P M L-R A R-\alpha$ fusion gene, younger age of onset, and a severe coagulopathy with a high incidence of early fatal hemorrhage $[1,2,4-7]$. White blood count (WBC) at presentation has been identified as the single most important prognostic factor for clinical outcome $[8,9]$.

All-trans retinoic acid (ATRA), a derivative of vitamin A, when combined with anthracycline-based chemotherapy yields a complete remission (CR) rate in excess of $90 \%$ in clinical trials involving patients with APL [9-11]. However,
ATRA has also been associated with several side effects, including skin problems (dryness, peeling, itching, and sun sensitivity), reversible elevation in liver enzymes, abnormal lipid levels, hypothyroidism, and headaches. Less commonly, ATRA has been associated with cerebral and myocardial infarction, corneal deposits secondary to hypercalcemia, scrotal ulcerations, Sweet's syndrome, Fournier's gangrene, APL differentiation syndrome, and pseudotumor cerebri (PC) $[5,7,9,12-14]$. PC is characterized by symptoms and signs of increased intracranial pressure, including headache, diplopia, and papilledema, with a normal cerebrospinal fluid (CSF) composition, and brain imaging findings [15-17]. (Table 1) Papilledema, though a common manifestation of $\mathrm{PC}$, is not an essential criterion for its diagnosis $[16,18]$. The exact pathogenesis of ATRA-induced PC has not been established $[19,20]$. Several previous studies report, that PC is a complication of ATRA therapy occurring predominantly in pediatric patients usually within 2 weeks of initiation of treatment [19]. 
TABLe 1: Modified Dandy criteria for diagnosis of pseudotumor cerebri [16].

(1) If symptoms and signs are present, they may only reflect those of generalized intracranial hypertension or papilledema.

The most common symptoms reflecting generalized intracranial hypertension are headache, pulsatile intracranial noises, and double vision. Symptoms reflecting papilledema include transient visual obscurations and peripheral visual loss.

(2) Elevated intracranial pressure must be documented with the patient lying in the lateral decubitus position.

A lumbar CSF opening pressure greater than $250 \mathrm{~mm} \mathrm{H} 2 \mathrm{O}$ is indicative of this disorder. Readings between $200 \mathrm{~mm}$ and $250 \mathrm{~mm} \mathrm{H} 2 \mathrm{O}$ are nondiagnostic.

(3) CSF must be normal.

There must be no evidence of pleocytosis, cellular atypia, or hypoglycorrhachia, and CSF protein levels should be normal.

(4) There must be no evidence of hydrocephalus, mass, structural, or vascular lesion on MRI or contrast-enhanced CT for typical patients and on an MRI and MR venography for atypical patients.

VST is rare in typical patients (i.e., an obese woman of childbearing age). Therefore, a CT is sufficient even though it cannot detect VST.

The incidence of VST and other vascular lesions increases significantly in atypical patients. Consequently, an MRI or MR venography scan is warranted given their heightened ability at detecting these differential disorders.

(5) No other cause of pseudotumor cerebri can be identified.

CSF; cerebral spinal fluid; MRI; magnetic resonance imaging; CT; computerized tomogram; and VST; venous sinus thrombosis

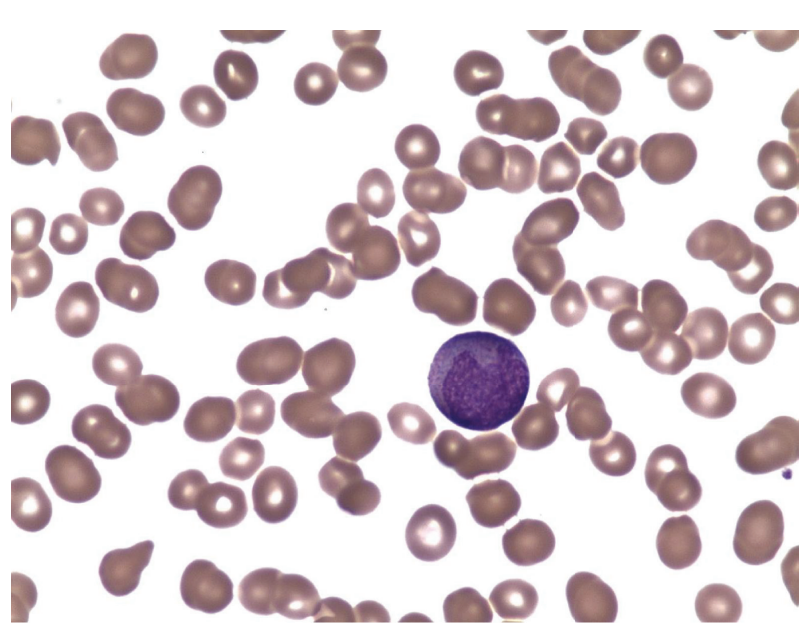

FIGURE 1: Peripheral blood film showing promyelocytes. The peripheral blood film revealed frequent promyelocytes, most of them with multiple Auer rods. Flow cytometric analysis confirmed that these cells were immature promyelocytes expressing CD45 (dim) CD33 (dim), and CD13 and negative for CD34, HLADR, CD14, CD15, CD64, and CD16. Additional FISH studies confirmed the presence of $\mathrm{t}(15 ; 17)$ PML-RARA fusion seen in acute promyelocytic leukemia.

Herein, we describe a case of ATRA-induced PC in a middle-aged woman which occurred while she was recovering from ATRA-based induction chemotherapy treatment for APL. We also review the current literature and discuss the managing principles of ATRA-induced PC.

\section{Case Report}

A previously healthy, but obese 38-year-old Native American female, sought surgical evaluation for a left ulnar nerve entrapment syndrome. A routine preoperative laboratory assessment demonstrated a hematocrit of $30 \%$, WBC of $3 \times$ $10 \% / \mathrm{L}$ (48\% lymphocytes, 6\% monocytes, $16 \%$ segmented polymorphonuclear cells, $25 \%$ promyelocytes, and $2 \%$ blasts) and a platelet count of $13 \times 10^{9} / \mathrm{L}$. Further blood test including a coagulation panel showed normal electrolytes and hepatic transaminases, mildly elevated serum lactate dehydrogenase at $298 \mathrm{U} / \mathrm{L}$, prothrombin time of $14.5 \mathrm{sec}-$ onds (normal 11-13.5), partial thromboplastin time of 35 seconds (normal 25-34), fibrinogen of $762 \mathrm{mg} / \mathrm{dL}$ (normal, 212-470), thrombin time of 13 seconds (normal, 15-19), and D-dimer $9.64 \mu \mathrm{g} / \mathrm{mL}$ (normal, <0.40). Peripheral blood film showed several circulating blasts with coarse reddishpurple granules and Auer rods in the cytoplasm, convoluted nuclei, prominent nucleoli and fine open chromatin consistent with promyelocytes. Bone marrow biopsy and aspirate revealed a hypercellular marrow dominated by sheets of promyelocytic-appearing blasts. (Figure 1) Immunohistochemical studies showed that the blasts were positive for CD117 and myeloperoxidase, stained dimly for CD45, and did not express HLA-DR. Cytogenetic analysis demonstrated the characteristic $\mathrm{t}(15 ; 17)$ translocation and FISH analysis confirmed the presence of a PML/RARA rearrangement. She began induction chemotherapy (idarubicin $12 \mathrm{mg} / \mathrm{m}^{2} /$ day IV, days $1-3$ and cytosine arabinoside [Ara-C] $100 \mathrm{mg} / \mathrm{m}^{2} /$ day IV, days $1-7$ ) in conjunction with ATRA ( $45 \mathrm{mg} / \mathrm{m}^{2}$ daily in two divided doses PO). On day 7, she was prescribed fluconazole $400 \mathrm{mg}$ daily and levofloxacin $500 \mathrm{mg}$ daily for antifungal and antibacterial prophylaxis, respectively. On day 17 , she reported a throbbing and persistent frontal headache which was accompanied by photosensitivity, nausea, and vomiting. Her neurologic exam was unremarkable. Ophthalmologic exam showed bilateral papilledema but no retinal hemorrhages. A lumbar puncture showed a CSF opening pressure of $300 \mathrm{~mm}$ of water (normal <200) with normal biochemical and cytologic findings. Magnetic resonance imaging of the brain was normal. ATRA was withheld and she received $1,000 \mathrm{mg}$ of acetazolamide twice daily in conjunction with standard antiemetics and analgesics. Over the course of the next week, her neurologic and ocular symptoms improved, but they did not completely resolve until 2 days after fluconazole was also discontinued. She has since completed consolidation 
chemotherapy consisting of two cycles of arsenic trioxide $(0.15 \mathrm{mg} / \mathrm{kg} / \mathrm{day}, \mathrm{IV}, 5$ days/week for 5 weeks $)$, followed by two cycles of ATRA $\left(45 \mathrm{mg} / \mathrm{m}^{2} /\right.$ day in two divided doses, PO, days $1-7)$ and daunorubicin $\left(50 \mathrm{mg} / \mathrm{m}^{2} \mathrm{IV}\right.$, days $1-3$ ) without recrudescent neurologic symptoms [21]. She then completed ATRA maintenance every other week for a year in conjunction with daily 6-mercaptopurine and weekly methotrexate [22]. She remains in clinical and molecular CR at 18 months of followup.

\section{Discussion}

$\mathrm{PC}$ is a rare disorder with an annual incidence of approximately 1 case per 100,000 people, but predominantly affects obese women of childbearing age [23]. It manifests with headache, nausea, and vomiting, as well as pulsatile tinnitus and diplopia. If untreated, it can cause swelling of the optic disc, which may lead to progressive optic atrophy and blindness [24]. Though the exact etiology of PC is not clear, several theories have been proposed such as increased production of CSF, increased blood flow to brain tissue, and increased venous outflow resistance [25]. Several medical conditions such as obstructive sleep apnea, pregnancy, Behcet's disease, and thyroid dysfunction have been implicated as risk factors for PC. Also, a number of medications have been casually associated with PC, including oral contraceptives, various antibiotics, thyroid replacement, corticosteroid withdrawal, and lithium [26-32]. Additionally, a strong link has been identified with administration of growth hormones, tetracycline and related compounds and vitamin A derivatives, including ATRA [15, 20, 33-36].

It is unclear how ATRA causes PC. One hypothesis suggests that retinoids enhance production of CSF and also alter the lipid constituents of choroid plexus and arachnoid villi, disrupting the normal transport systems and impeding the absorption of CSF [37]. The maximum tolerated ATRA dose in adults is $150 \mathrm{mg} / \mathrm{m} 2 /$ day, and $45-60 \mathrm{mg} / \mathrm{m}^{2} /$ day for children, but PC has occurred at much lower doses in both groups $[13,14,38]$. ATRA is oxidized by the cytochrome P-450 system including isoforms CYP2C8, CYP2C9, and CYP3A4. Concomitant administration of drugs that inhibit or are metabolized by this system, most notably triazole antifungals, can lead to toxic ATRA concentrations $[39,40]$.

To identify further cases of ATRA-induced PC, we performed a systematic review of peer-reviewed publications using Medical Subject Headings (MeSH), PubMed/Medline, and Google Scholar databases. Keywords were used alone and with the modifiers of "acute promyelocytic leukemia," "pseudotumor cerebri," and "tretinoin" or "all-trans retinoic acid." We also examined the bibliographies of each relevant article for additional references. Only publications in English were incorporated in our review. Including our index patient, we identified 21 case reports of PC occurring in patients who received ATRA as a component of APL treatment [14, 19, 20, 38, 40-56]. We identified another 20 reports of ATRAinduced PC in larger scale studies. The cohort size of these studies ranged from 9 to 576 (median: 26) and included a total of 763 patients $[13,55,57-62]$. Nevertheless, adequate information regarding the patients' clinical presentation and outcome was available in only two instances $[13,62]$. We, therefore, accumulated and analyzed data from 23 cases (Table 2).

The median age at diagnosis of PC was 27 years for females (range: 6 to 38 years) and 16 years for males (range: 4 to 43 years) with a slightly higher preponderance of incidence among females (female to male ratio of $1.3: 1$ ). Data about the role of body mass index (BMI), in ATRA-induced PC was not readily available; only three case reports provided information regarding patients' BMI, which were reportedly normal. As defined by the Centers for Disease Control and Prevention, our patient was obese (BMI 32) [63].

Neurologic symptoms were reported in 22 of the patients, of whom all complained of headache, 11 (50\%) had diplopia (often with cranial nerve VI palsy), and 7 (32\%) had nausea and vomiting. Less common complaints that led to a diagnosis of PC were blurred or distorted vision (23\%), photosensitivity (9\%), tinnitus (5\%), and convergent strabismus (5\%). Presenting signs of PC were described in 21 cases and included $5(24 \%)$ with visual field changes such as blind spot enlargement and decreased visual acuity. Papilledema was a uniform finding in the 21 cases in which retinal exams were described.

The median time to the diagnosis of PC after beginning of ATRA therapy was 14 days. (Range: 7 days to 10 months) (Table 2) PC most often occurred during induction therapy ( $n=18,78 \%$ ) but also occurred during consolidation therapy $(n=3,13 \%)$ and during maintenance therapy $(n=8$, $35 \%)$.

Strategies for treating PC were provided in all 23 cases. For 17 patients (74\%), ATRA was withheld soon after PC was recognized. ATRA was also withheld in three other cases but only after other therapeutic interventions were first implemented. In 7 of the 20 cases (35\%) where ATRA was held, $\mathrm{PC}$ resolved with no further treatment. In the 13 other cases, signs and symptoms resolved following therapeutic lumbar punctures (5 of 13 cases, $38 \%$ ) and the use of medications, most notably diuretics-mannitol, glycerin, and acetazolamide (11,85\%); corticosteroids (4, 31\%); and/or analgesics (3, 23\%). Neurologic symptoms resolved within a median of seven days (range: $1 / 2$ day to 25 weeks) after ATRA was discontinued.

In three cases, ATRA was continued despite the diagnosis of PC. In one instance, the patient was treated with acetazolamide alone. Papilledema resolved within a month, although he continued to have visual complaints at three months followup. In the other two instances, individuals were managed with high-volume therapeutic lumbar punctures; neurologic symptoms and increased cranial pressure resolved within five and seven days, respectively. Including our index patient, a total of eight patients (35\%) were rechallenged with ATRA after their neurologic condition improved. In all but our index case, PC symptoms recurred after patients were rechallenged with ATRA, yet in two of these cases PC symptoms were sufficiently mild that no therapeutic intervention was required. CNS symptoms resolved in three of the other five cases following acetazolamide use. ATRA withdrawal and subsequent reintroduction at a reduced dose 


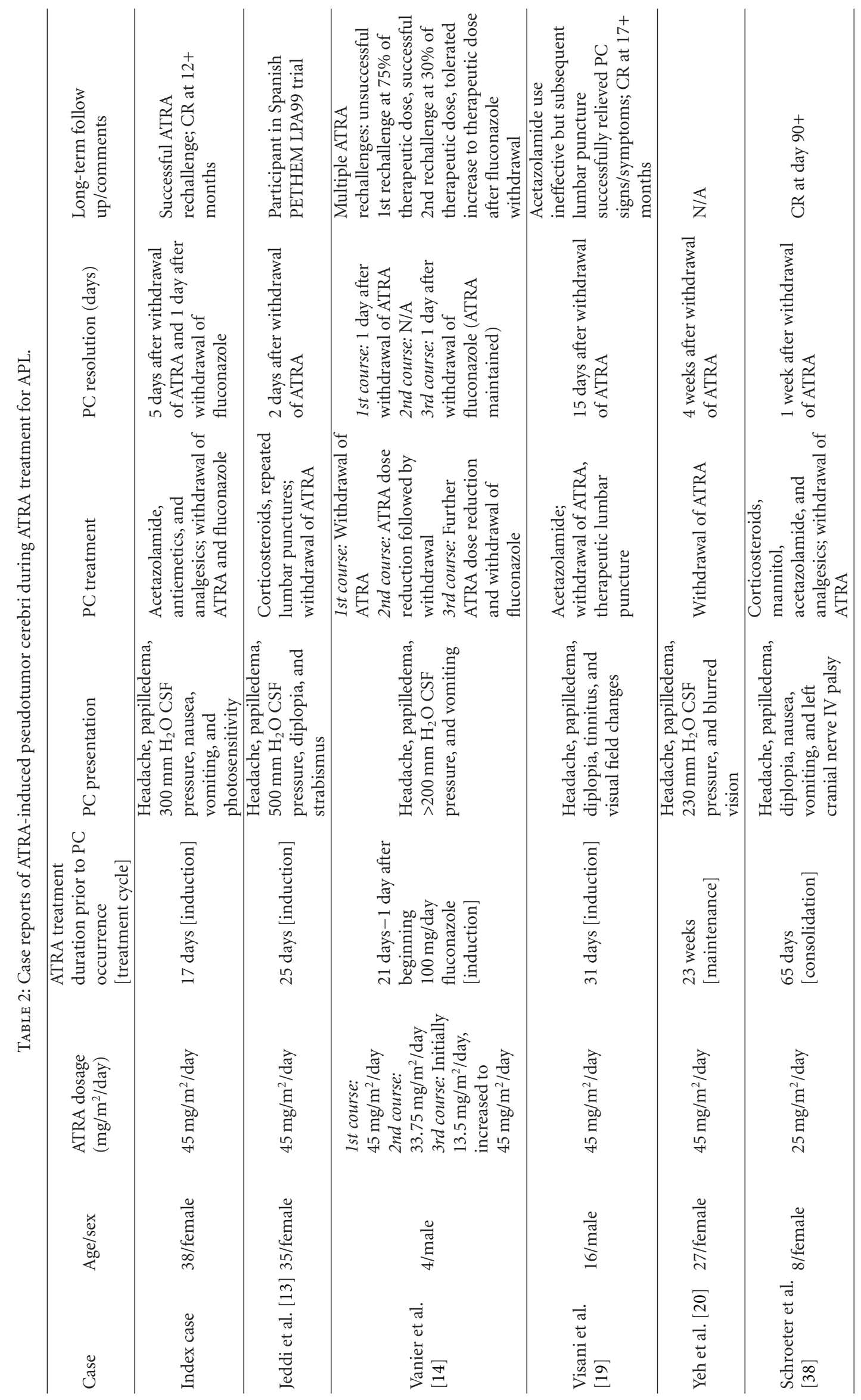




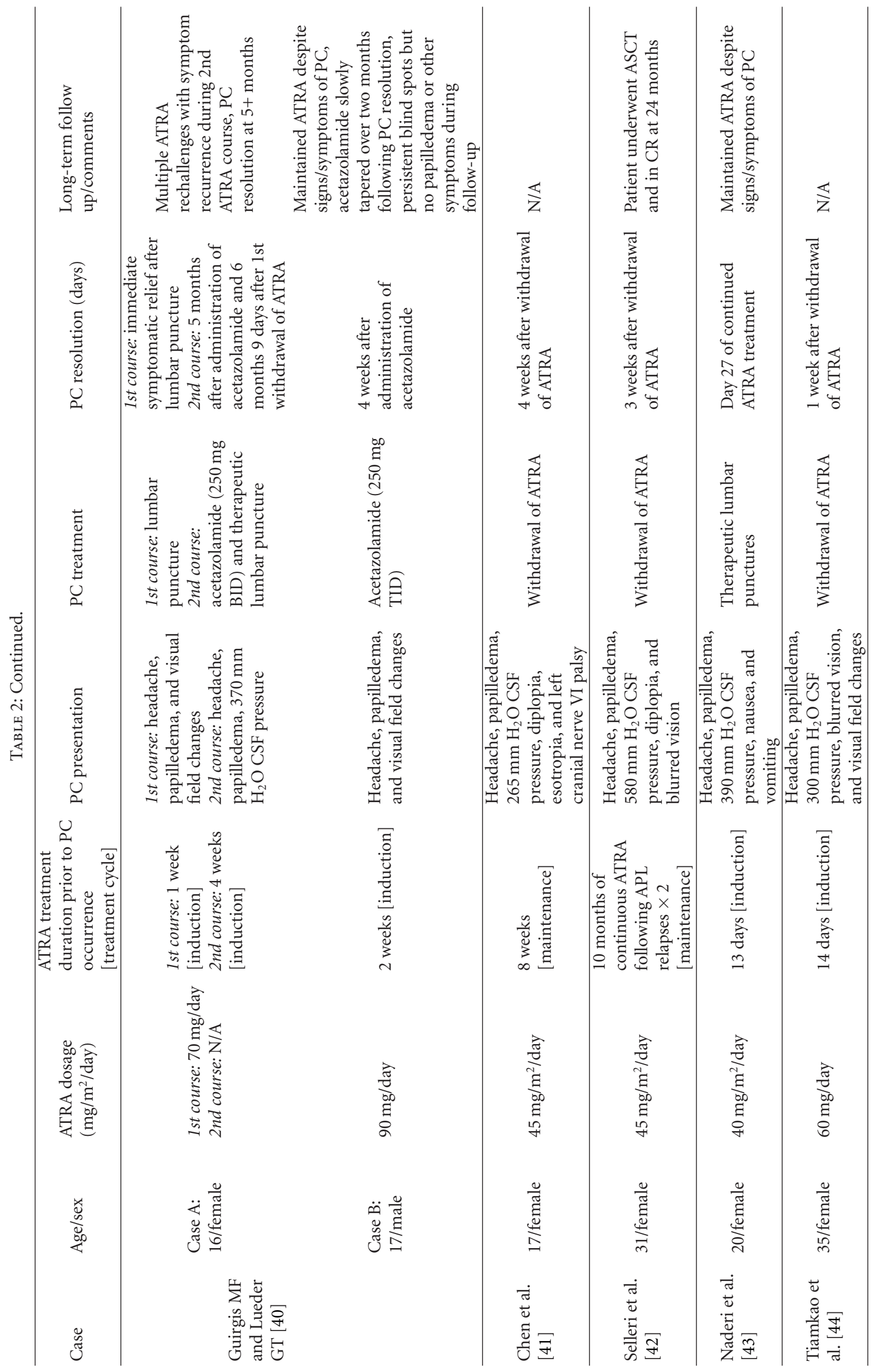




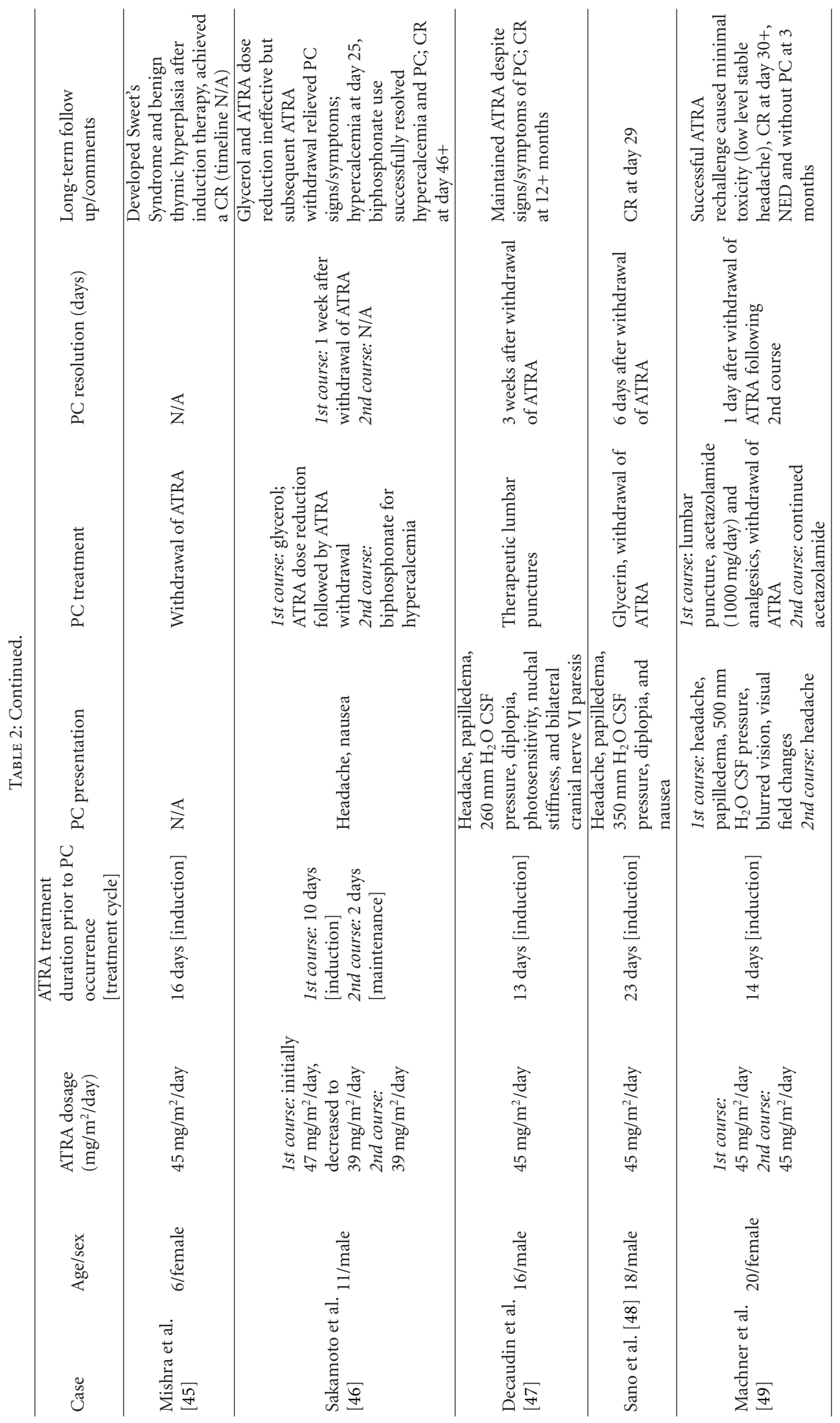




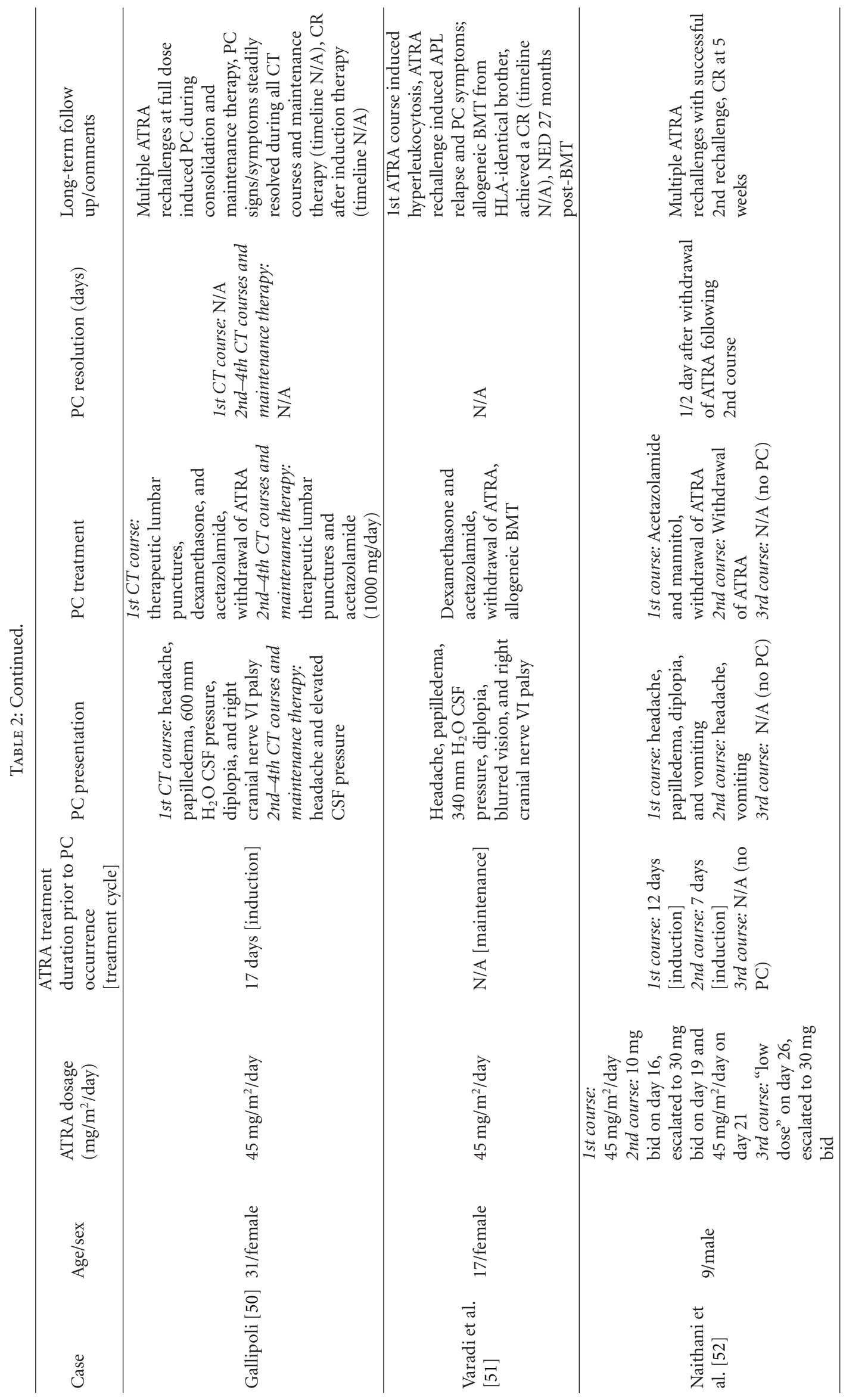




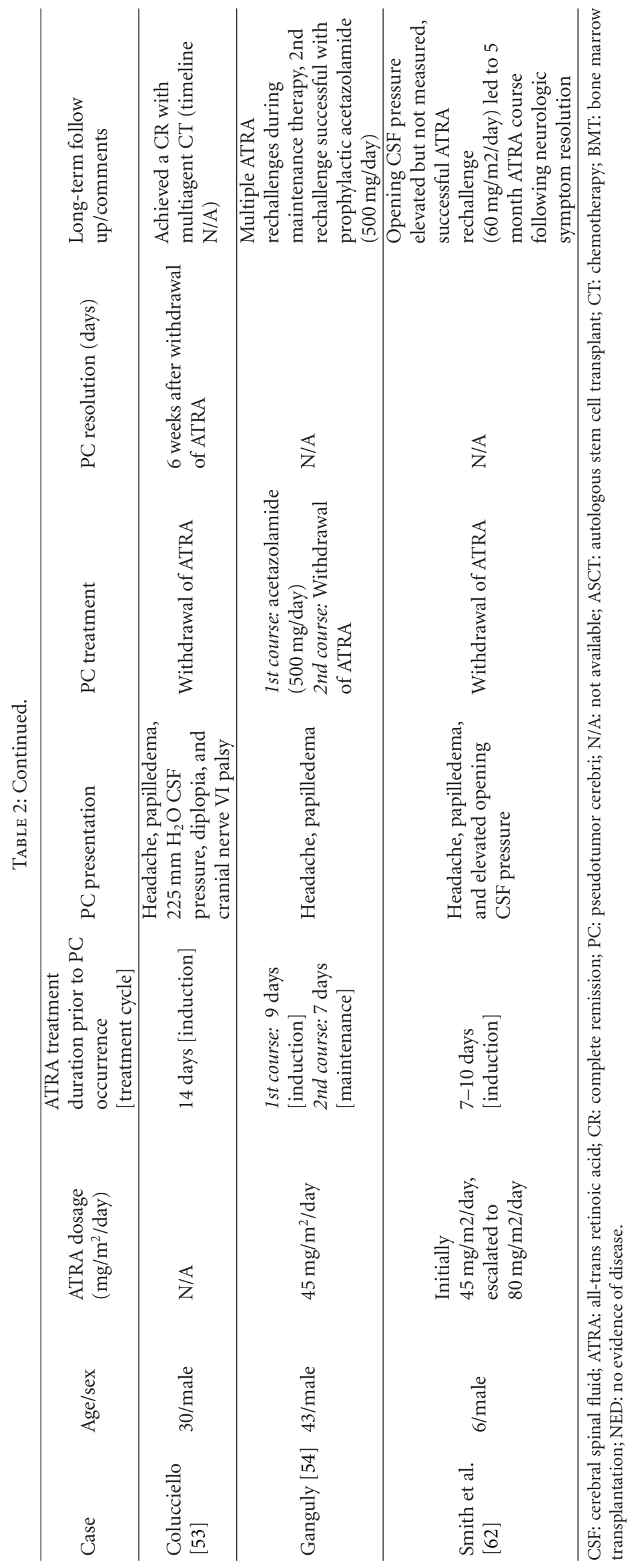


TABle 3: Common drug interactions with tretinoin [39].

\begin{tabular}{|c|c|}
\hline $\operatorname{Drug}(\mathrm{s})$ & Interaction \\
\hline $\begin{array}{l}\text { Antifibrinolytic agents (e.g., aminocaproic acid, aprotinin, } \\
\text { and tranexamic acid) }\end{array}$ & May increase risk of thrombosis during tretinoin therapy. \\
\hline $\begin{array}{l}\text { Drugs that induce cytochrome P- } 450 \text { system (e.g., } \\
\text { barbiturates, carbamazepine, phenytoin, primidone, } \\
\text { rifabutin, and rifampin) }\end{array}$ & May decrease tretinoin concentrations and antineoplastic efficacy. \\
\hline $\begin{array}{l}\text { Drugs that inhibit cytochrome P-450 (e.g., cimetidine, } \\
\text { erythromycin, fluconazole, and ketoconazole) }\end{array}$ & $\begin{array}{l}\text { May increase tretinoin concentrations and toxicity. Adjust tretinoin } \\
\text { concentrations when necessary. }\end{array}$ \\
\hline $\begin{array}{l}\text { Drugs that inhibit CYP-2C8 (e.g., atazanavir, gemfibrozil, } \\
\text { and ritonavir) }\end{array}$ & $\begin{array}{l}\text { May increase tretinoin concentrations and toxicity. Adjust tretinoin } \\
\text { concentrations when necessary. }\end{array}$ \\
\hline Estrogen-progestin oral contraceptives & $\begin{array}{l}\text { Tretinoin may decrease contraceptive efficacy. The use of at least } 1 \text { other } \\
\text { effective form of contraception during tretinoin therapy is recommended. }\end{array}$ \\
\hline Progestin-only oral contraceptives & $\begin{array}{l}\text { Tretinoin may decrease contraceptive efficacy. The use of at least } 2 \text { other } \\
\text { effective forms of contraception during tretinoin therapy is recommended. }\end{array}$ \\
\hline $\begin{array}{l}\text { Tetracycline antibiotics (e.g., doxycycline, minocycline, } \\
\text { and tetracycline) }\end{array}$ & May increase risk of PC. \\
\hline Ethanol & May increase CNS depression. Avoid concomitant use. \\
\hline Hydroxyurea & $\begin{array}{l}\text { Synergistic antineoplastic effects; may increase risk of cell lysis and potentially } \\
\text { fatal bone marrow necrosis. }\end{array}$ \\
\hline St. John's wort & $\begin{array}{l}\text { May decrease tretinoin concentrations and antineoplastic efficacy. Avoid } \\
\text { concomitant use. }\end{array}$ \\
\hline Vitamin A & Increased risk of vitamin A toxicity. Avoid combination. \\
\hline
\end{tabular}

and prophylactic administration of acetazolamide prior to a subsequent ATRA rechallenge are additional strategies that clinicians have used in the context of PC treatment.

PC through inhibition of CYP enzymes and potentiation of ATRA by triazole antifungals has been described previously in only two instances $[14,56]$. In retrospect, our patient had multiple risk factors for PC. She was an obese premenopausal female who received ATRA for treatment of APL. In addition, she received highdoses of fluconazole for antifungal prophylaxis while she was receiving ATRA. This may have played an important role in promoting PC by increasing ATRA drug levels (Table 3). Of note, her symptoms improved partially after we withheld ATRA but did not resolve completely until 48 hours after fluconazole was also discontinued.

\section{Conclusion}

In summary, PC is a well-described syndrome which classically has been associated with obese women of childbearing age. Although the pathogenesis is not well understood, it has also been frequently reported in the context of ATRA treatment for APL. In our literature survey, treatment of PC most often included suspension of ATRA until neurologic symptoms abated. For patients with PC whose neurologic complaints do not improve after withholding ATRA, use of acetazolamide, therapeutic high-volume lumbar punctures, dexamethasone, and analgesics may be useful. Patients may be rechallenged with ATRA once neurologic complaints improve, but symptoms recur in most cases. Since ATRA is an important component of all phases of APL treatment, use of prophylactic acetazolamide prior to a subsequent ATRA rechallenge may mitigate risk of recrudescent PC.
Drug interactions, including the one we highlight in this case report between triazole antifungals such as fluconazole and ATRA, must also be kept in mind because fluconazole is a commonly used antifungal agent which is often employed during treatment of acute leukemia.

\section{Conflict of Interests}

The authors declare no conflict of interests.

\section{References}

[1] R. M. Stone and R. J. Mayer, "The unique aspects of acute promyelocytic leukemia," Journal of Clinical Oncology, vol. 8, no. 11, pp. 1913-1921, 1990.

[2] R. P. Warrell Jr., H. De The, Z. Y. Wang, and L. Degos, "Acute promyelocytic leukemia," New England Journal of Medicine, vol. 329, no. 3, pp. 177-189, 1993.

[3] F. R. Davey, R. B. Davis, J. M. MacCallum et al., "Morphologic and cytochemical characteristics of acute promyelocytic leukemia," American Journal of Hematology, vol. 30, no. 4, pp. 221-227, 1989.

[4] R. A. Larson, K. Kondo, and J. W. Vardiman, "Evidence for a $15 ; 17$ translocation in every patient with acute promyelocytic leukemia," American Journal of Medicine, vol. 76, no. 5, pp. 827-841, 1984.

[5] R. Mertelsmann, H. T. Thaler, and L. To, "Morphological classification, response to therapy, and survival in 263 adult patients with acute nonlymphoblastic leukemia," Blood, vol. 56, no. 5, pp. 773-781, 1980.

[6] G. J. Ventura, J. P. Hester, D. O. Dixon, S. Khorana, and M. J. Keating, "Analysis of risk factors for fatal hemorrhage during induction therapy of patients with acute promyelocytic leukemia," Hematologic Pathology, vol. 3, no. 1, pp. 23-28, 1989. 
[7] M. S. Tallman, J. W. Andersen, C. A. Schiffer et al., "All-transretinoic acid in acute promyelocytic leukemia," New England Journal of Medicine, vol. 337, no. 15, pp. 1021-1028, 1997.

[8] M. Tallman, D. Douer, S. Gore et al., "Treatment of patients with acute promyelocytic leukemia: a consensus statement on risk-adapted approaches to therapy," Clinical Lymphoma, $M y$ eloma and Leukemia, vol. 10, supplement 3, pp. S122-S126, 2010.

[9] F. Lo-Coco, G. Avvisati, M. Vignetti et al., "Front-line treatment of acute promyelocytic leukemia with AIDA induction followed by risk-adapted consolidation for adults younger than 61 years: results of the AIDA-2000 trial of the GIMEMA Group," Blood, vol. 116, no. 17, pp. 3171-3179, 2010.

[10] P. Fenaux, C. Chastang, S. Chevret et al., "A randomized comparison of all transretinoic acid (ATRA) followed by chemotherapy and ATRA plus chemotherapy and the role of maintenance therapy in newly diagnosed acute promyelocytic leukemia," Blood, vol. 94, no. 4, pp. 1192-1200, 1999.

[11] M. A. Sanz, D. Grimwade, M. S. Tallman et al., "Management of acute promyelocytic leukemia: recommendations from an expert panel on behalf of the European LeukemiaNet," Blood, vol. 113, no. 9, pp. 1875-1891, 2009.

[12] S. Simzar, A. M. Rotunda, and N. Craft, "Scrotal ulceration as a consequence of all-trans-retinoic acid (ATRA) for the treatment of acute promyelocytic leukemia," Journal of Drugs in Dermatology, vol. 4, no. 2, pp. 231-232, 2005.

[13] R. Jeddi, K. Kacem, H. B. Neji et al., "Predictive factors of all-trans-retinoic acid related complications during induction therapy for acute promyelocytic leukemia," Hematology, vol. 13, no. 3, pp. 142-146, 2008.

[14] K. L. Vanier, A. J. Mattiussi, and D. L. Johnston, "Interaction of all-trans-retinoic acid with fluconazole in acute promyelocytic leukemia," Journal of Pediatric Hematology/Oncology, vol. 25, no. 5, pp. 403-404, 2003.

[15] E. R. G. Ang, J. C. C. Zimmerman, and E. Malkin, "Pseudotumor cerebri secondary to minocycline intake," Journal of the American Board of Family Practice, vol. 15, no. 3, pp. 229-233, 2002.

[16] D. I. Friedman and D. M. Jacobson, "Diagnostic criteria for idiopathic intracranial hypertension," Neurology, vol. 59, no. 10, pp. 1492-1495, 2002.

[17] A. G. Lee and M. Wall, Idiopathic Intracranial Hypertension (Pseudotumor Cerebri): Clinical Features and Diagnosis, UpToDate, Waltham, Mass, USA, 2010.

[18] S. J. Wang, S. D. Silberstein, S. Patterson, and W. B. Young, "Idiopathic intracranial hypertension without papilledema: a case- control study in a headache center," Neurology, vol. 51, no. 1, pp. 245-249, 1998.

[19] G. Visani, G. Bontempo, S. Manfroi, A. Pazzaglia, R. D'Alessandro, and S. Tura, "All-trans-retinoic acid and pseudotumor cerebri in a young adult with acute promyelocytic leukemia: a possible disease association," Haematologica, vol. 81, no. 2, pp. 152-154, 1996.

[20] Y. C. Yeh, H. F. Tang, and I. M. Fang, "Pseudotumor cerebri caused by all-trans-retinoic acid treatment for acute promyelocytic leukemia," Japanese Journal of Ophthalmology, vol. 50, no. 3, pp. 295-296, 2006.

[21] B. L. Powell, B. Moser, W. Stock et al., "Arsenic trioxide improves event-free and overall survival for adults with acute promyelocytic leukemia: North American Leukemia Intergroup Study C9710," Blood, vol. 116, no. 19, pp. 3751-3757, 2010.

[22] M. S. Tallman, J. W. Andersen, C. A. Schiffer et al., "All-trans retinoic acid in acute promyelocytic leukemia: long-term outcome and prognostic factor analysis from the North American Intergroup protocol," Blood, vol. 100, no. 13, pp. 42984302, 2002.

[23] M. Jindal, L. Hiam, A. Raman, and D. Rejali, "Idiopathic intracranial hypertension in otolaryngology," European Archives of Oto-Rhino-Laryngology, vol. 266, no. 6, pp. 803-806, 2009.

[24] D. K. Binder, J. C. Horton, M. T. Lawton et al., "Ideopathic intracranial hypertension," Neurosurgery, vol. 54, no. 3, pp. 538-552, 2004.

[25] G. A. Bateman, S. A. Stevens, and J. Stimpson, "A mathematical model of idiopathic intracranial hypertension incorporating increased arterial inflow and variable venous outflow collapsibility: clinical article," Journal of Neurosurgery, vol. 110, no. 3, pp. 446-456, 2009.

[26] B. Ireland, J. J. Corbett, and R. B. Wallace, "The search for causes of idiopathic intracranial hypertension. A preliminary case-control study," Archives of Neurology, vol. 47, no. 3, pp. 315-320, 1990.

[27] V. Giuseffi, M. Wall, P. Z. Siegel, and P. B. Rojas, "Symptoms and disease associations in idiopathic intracranial hypertension (pseudotumor cerebri): a case-control study," Neurology, vol. 41, no. 2, pp. 239-244, 1991.

[28] I. U. Scott, R. M. Siatkowski, M. Eneyni, M. C. Brodsky, and B. L. Lam, "Idiopathic intracranial hypertension in children and adolescents," American Journal of Ophthalmology, vol. 124, no. 2, pp. 253-255, 1997.

[29] P. J. Francis, S. Haywood, S. Rigden, D. M. Calver, and G. Clark, "Benign intracranial hypertension in children following renal transplantation," Pediatric Nephrology, vol. 18, no. 12, pp. 1265-1269, 2003.

[30] J. Serratrice, B. Granel, J. Conrath et al., "Benign intracranial hypertension and thyreostimulin suppression hormonotherapy," American Journal of Ophthalmology, vol. 134, no. 6, pp. 910-911, 2002.

[31] M. R. Rickels and C. W. Nichols, "Pseudotumor cerebri in patients with cushing's disease," Endocrine Practice, vol. 10, no. 6, pp. 492-496, 2004.

[32] S. H. Levine and C. Puchalski, "Pseudotumor cerebri associated with lithium therapy in two patients," Journal of Clinical Psychiatry, vol. 51, no. 6, pp. 251-253, 1990.

[33] S. L. Blethen, "Complications of growth hormone therapy in children," Current Opinion in Pediatrics, vol. 7, no. 4, pp. 466471, 1995.

[34] G. D. Reeves and D. A. Doyle, "Growth hormone treatment and pseudotumor cerebri: coincidence or close relationship?" Journal of Pediatric Endocrinology and Metabolism, vol. 15, supplement 2, pp. 723-730, 2002.

[35] D. J. Friedman, "Medication-induced intracranial hypertension in dermatology," American Journal of Clinical Dermatology, vol. 6, no. 1, pp. 29-37, 2005.

[36] F. W. Fraunfelder, F. T. Fraunfelder, and J. J. Corbett, "Isotretinoin-associated intracranial hypertension," Ophthalmology, vol. 111, no. 6, pp. 1248-1250, 2004.

[37] R. H. Spector and J. Carlisle, "Pseudotumor cerebri caused by a synthetic vitamin A preparation," Neurology, vol. 34, no. 11, pp. 1509-1511, 1984.

[38] T. Schroeter, C. Lanvers, H. Herding, and M. Suttorp, "Pseudotumor cerebri induced by all-trans-retinoic acid in a child treated for acute promyelocytic leukemia," Medical and Pediatric Oncology, vol. 34, no. 4, pp. 284-286, 2000.

[39] Tretinoin, 2011, http://www.factsandcomparisons.com/factscomparisons-online.aspx.

[40] M. F. Guirgis and G. T. Lueder, "Intracranial hypertension secondary to all-trans retinoic acid treatment for leukemia: 
diagnosis and management," Journal of the American Association for Pediatric Ophthalmology and Strabismus, vol. 7, no. 6, pp. 432-434, 2003.

[41] H. Y. Chen, R. K. Tsai, and S. M. Huang, "ATRA-induced pseudotumour cerebri-one case report," Kaohsiung Journal of Medical Sciences, vol. 14, no. 1, pp. 58-60, 1998.

[42] C. Selleri, F. Pane, R. Notaro et al., "All-trans-retinoic acid (ATRA) responsive skin relapses of acute promyelocytic leukaemia followed by ATRA-induced pseudotumour cerebri," British Journal of Haematology, vol. 92, no. 4, pp. 937-940, 1996.

[43] S. Naderi, S. Nukala, F. Marruenda, P. Kudarvalli, and P. R. Koduri, "Pseudotumour cerebri in acute promyelocytic leukemia: improvement despite continued ATRA therapy," Annals of Hematology, vol. 78, no. 7, pp. 333-334, 1999.

[44] S. Tiamkao and C. Sirijirachai, "Pseudotumor cerebri caused by all-trans-retinoic acid: a case report," Journal of the Medical Association of Thailand, vol. 83, no. 11, pp. 1420-1423, 2000.

[45] S. K. Mishra, S. R. Melinkeri, and S. Dabadghao, "Benign thymic hyperplasia after chemotherapy for acute myeloid leukemia," European Journal of Haematology, vol. 67, no. 4, pp. 252-254, 2001.

[46] O. Sakamoto, M. Yoshinari, T. Rikiishi et al., "Hypercalcemia due to all-trans retinoic acid therapy for acute promyelocytic leukemia: a case report of effective treatment with bisphosphonate," Pediatrics International, vol. 43, no. 6, pp. 688-690, 2001.

[47] D. Decaudin, Adams D, P. Naccache, L. Castagna, and J. N. Munck, "Maintained all-trans retinoic acid therapy in a patient with pseudotumour cerebri despite aggravated symptoms," Leukemia and Lymphoma, vol. 27, no. 3-4, pp. 373-374, 1997.

[48] F. Sano, K. Tsuji, N. Kunika et al., "Pseudotumor cerebri in a patient with acute promyelocytic leukemia during treatment with all-trans retinoic acid," Internal Medicine, vol. 37, no. 6, pp. 546-549, 1998.

[49] B. Machner, B. Neppert, M. Paulsen, C. Hofmann, T. Sander, and C. Helmchen, "Pseudotumor cerebri as a reversible side effect of all-trans retinoic acid treatment in acute promyelocytic leukaemia," European Journal of Neurology, vol. 15, no. 7, pp. e68-e69, 2008.

[50] P. Gallipoli, "Pseudotumour cerebri as a manageable side effect of prolonged all-trans retinoic acid therapy in an adult patient with acute promyelocytic leukaemia," European Journal of Haematology, vol. 82, no. 3, pp. 242-243, 2009.

[51] G. Varadi, A. Lossos, R. Or, J. Kapelushnik, and A. Nagler, "Successful allogeneic bone marrow transplantation in a patient with ATRA-induced pseudotumor cerebri," American Journal of Hematology, vol. 50, no. 2, pp. 147-148, 1995.

[52] R. Naithani, R. Kumar, and P. Mishra, "Pseudotumor cerebri in a child in early phase of induction therapy for APL with ATRA," Indian Journal of Pediatrics, vol. 76, no. 4, pp. 439-440, 2009.

[53] M. Colucciello, "Pseudotumor cerebri induced by all-trans retinoic acid treatment of acute promyelocytic leukemia," Archives of Ophthalmology, vol. 121, no. 7, pp. 1064-1065, 2003.

[54] S. Ganguly, "All-trans retinoic acid related headache in patients with acute promyelocytic leukemia: prophylaxis and treatment with acetazolamide," Leukemia Research, vol. 29, no. 6, p. 721, 2005.

[55] S. De Botton, V. Coiteux, S. Chevret et al., "Outcome of childhood acute promyelocytic leukemia with all-trans-retinoic acid and chemotherapy," Journal of Clinical Oncology, vol. 22, no. 8, pp. 1404-1412, 2004.

[56] K. S. Dixon and A. Hassoun, "Pseudotumor cerebri due to the potentiation of all-trans retinoic acid by voriconazole," Journal of the American Pharmacists Association, vol. 50, no. 6, pp. 742$744,2010$.

[57] H. H. Mahmoud, C. A. Hurwitz, W. M. Roberts, V. M. Santana, R. C. Ribeiro, and R. A. Krance, "Tretinoin toxicity in children with acute promyelocytic leukaemia," The Lancet, vol. 342, no. 8884, pp. 1394-1395, 1993.

[58] M. D. Čolović, G. M. Janković, I. Elezović et al., "Effect of alltrans-retinoic acid alone or in combination with chemotherapy in newly diagnosed acute promyelocytic leukaemia," Medical Oncology, vol. 14, no. 2, pp. 65-72, 1997.

[59] G. Mann, D. Reinhardt, J. Ritter et al., "Treatment with alltrans retinoic acid in acute promyelocytic leukemia reduces early deaths in children," Annals of Hematology, vol. 80, no. 7, pp. 417-422, 2001.

[60] A. Bapna, R. Nair, K. S. Tapan et al., "All-trans-retinoic acid (ATRA): pediatric acute promyelocytic leukemia," Pediatric Hematology and Oncology, vol. 15, no. 3, pp. 243-248, 1998.

[61] R. P. Warrell Jr., S. R. Frankel, W. H. Miller et al., "Differentiation therapy of acute promyelocytic leukemia with tretinoin (all-trans-retinoic acid)," New England Journal of Medicine, vol. 324, no. 20, pp. 1385-1393, 1991.

[62] M. A. Smith, P. C. Adamson, F. M. Balis et al., "Phase I and pharmacokinetic evaluation of all-trans-retinoic acid in pediatric patients with cancer," Journal of Clinical Oncology, vol. 10, no. 11, pp. 1666-1673, 1992.

[63] "Healthy Weight-it's not a diet, it's a lifestyle!," 2011, http:// www.cdc.gov/healthyweight/index.html. 


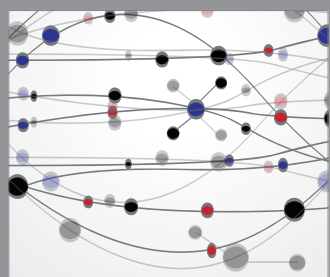

The Scientific World Journal
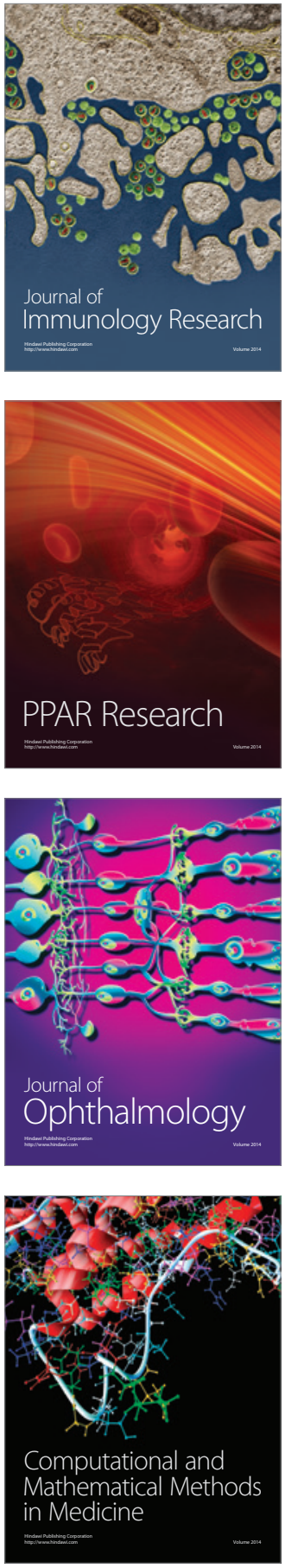

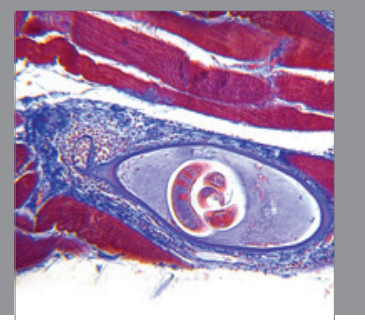

Gastroenterology

Research and Practice
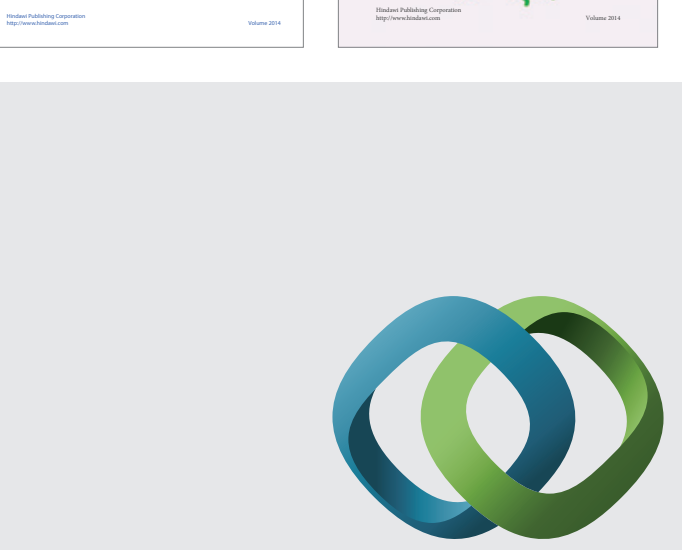

\section{Hindawi}

Submit your manuscripts at

http://www.hindawi.com
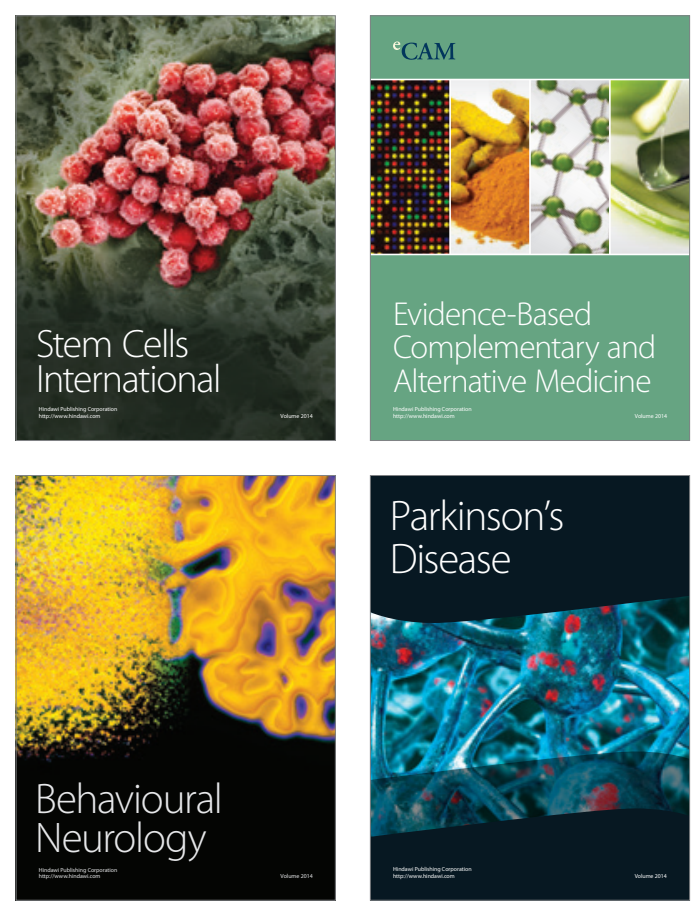

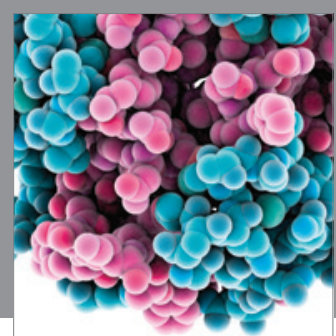

Journal of
Diabetes Research

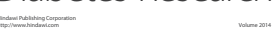

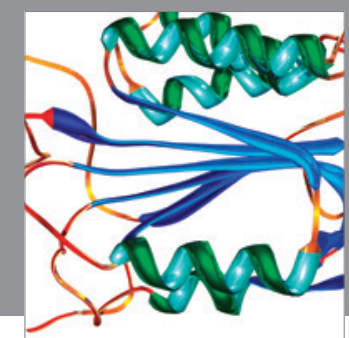

Disease Markers
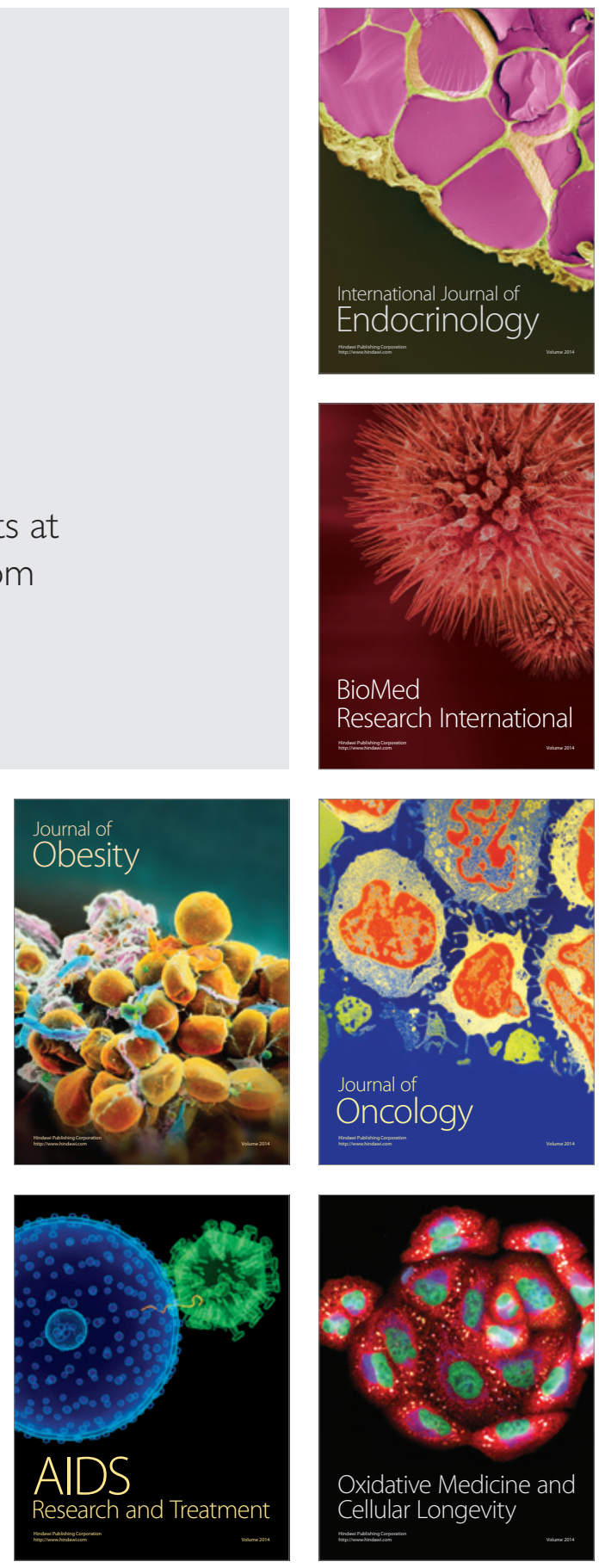